\title{
Desafios metodológicos e formativos em pesquisa com mulheres na prisão
}

Methodological and formative challenges in research with women in prison

Retos metodológicos y formativos en la investigación con mujeres en prisión

\author{
Caroline Cabral Nunes
}

João Paulo Macedo

Universidade Federal do Delta do Parnaíba (UFDPar), Parnaíba, PI, Brasil

\begin{abstract}
Resumo
Propõe discussão acerca dos desafios metodológicos e formativos em pesquisa-intervenção ao investigar as relações de poder que incidem sobre os corpos femininos na prisão. Objetiva apresentar como a investigação foi tecida e atravessada pelos encontros-acontecimentos com 12 mulheres numa prisão mista, por meio de observações, registro em diários de campo e realização de entrevistas coletivas. Três blocos de discussão abordam os atravessamentos e aprendizagens para realizar pesquisas com mulheres na prisão: modulações no corpoexperiência para cultivar outras percepções e aprendizagens no fazer-pesquisa; deslocamentos subjetivos e experimentações no caminhar da pesquisa; e discutindo os deslocamentos de si no processo de escrita acadêmica de uma pesquisa coproduzida com mulheres na prisão.
\end{abstract}

Palavras chave: Pesquisa-Intervenção; Presídios Mistos; Mulheres.

\begin{abstract}
Proposes discussion of the methodological and formative challenges in research-intervention when investigating the power relations that affect female bodies in prison. Aims to present how the research was woven and crossed by the encounters-events with 12 women in a mixed prison, through observations, recording in field journals and conducting group interviews. Three blocks of discussion address the crossings and learnings in conducting research with women in prison: modulating body-experience to cultivate other perceptions and learnings in doing research; subjective shifts and experimentation in the journey of research; and discussing self-shifts in the academic writing process of co-produced research with women in prison.
\end{abstract}

Keywords: Intervention Research; Mixed Prisons; Women. 


\section{Resumen}

Propone la discusión de los desafíos metodológicos y formativos de la investigaciónintervención al investigar las relaciones de poder que afectan a los cuerpos de las mujeres en prisión. Tiene por objeto presentar cómo se tejió la investigación y se cruzó por los encuentros-eventos con 12 mujeres en una prisión mixta, a través de observaciones, registro en diarios de campo y realización de entrevistas de grupo. Tres bloques de discusión abordan los cruces y aprendizajes en la realización de investigaciones con mujeres en prisión: la modulación de la experiencia corporal para cultivar otras percepciones y aprendizajes en la realización de investigaciones; los cambios subjetivos y la experimentación en el viaje de investigación; y la discusión de los cambios propios en el proceso de escritura académica de investigaciones coproducidas con mujeres en prisión.

Palabras-clave: Intervención-Investigación; Prisiones Mixtas; Mujeres.

\section{Introdução}

O sistema penitenciário brasileiro não cansa de sinalizar sua falência diante do cenário recorrente de superlotação, precariedade, insalubridade e violência. Isso porque, como diria Foucault (2014a), a prisão nunca errou seu alvo, pelo contrário, existe para gerir ilegalidades e difundir sua lógica punitiva, com extensão normalizadora no tecido social. Por isso, não convém exigir a humanização de um sistema que tem em sua estrutura "falhas" históricas que foram incorporadas enquanto lógica de funcionamento, a exemplo do encarceramento em massa, da seletividade penal, da morosidade da justiça e o elevado número de presos provisórios (não sentenciados) que se arrasta no país (Santos, 2019). Sem dúvida, as prisões brasileiras tornaram-se locais de deterioração da condição humana, tanto da população carcerária quanto dos agentes do sistema penal, revelando-se um projeto inviável para reintegrar, reeducar, ressocializar, porém, bastante exitoso em sua finalidade para punir (Zaffaroni, 2013). Esse quadro reflete-se no fato de o Brasil ocupar a terceira posição entre os que mais encarceram no mundo, acompanhado do alarmante índice de reincidência de egressos do sistema ou de presos com mais de uma condenação (Ferraz \& Joffily, 2019). De acordo com o Levantamento de Informações Penitenciárias (Infopen), o Brasil registrou no ano de 2017 o total de 726.354 pessoas presas, sendo que o sistema conta com 303.112 vagas (Brasil, 2019).Cabe alertar que, nos últimos anos, constatou-se um maior crescimento da população carcerária feminina $(656 \%)$ em relação à masculina (293\%) (Brasil, 2018), chamando atenção para discussões acerca de um processo de feminização da pobreza e criminalização da mulher com o seu massivo encarceramento (Germano, Monteiro, \& Liberato, 2018). 
No tocante ao perfil das mulheres presas, muitas são jovens, com idade até $29 \operatorname{anos}(44,77 \%)$, pardas/negras $(59,55 \%)$, solteiras $(58,55 \%)$, possuem filhos $(74 \%)$, contam somente com o ensino fundamental completo/incompleto $(57,91 \%)$ e, quando muito, concluíram ou não o ensino médio $(29,75 \%)$ (Brasil, 2018). Os dados ainda indicam que em relação ao tipo de pena, a maior parte está presa pelo crime de tráfico de drogas (60\%), tendo sido flagradas com pequena quantidade para comercialização enquanto meio de sustento. Além disso, cerca de 38\% das mulheres presas nas penitenciárias brasileiras não têm sentença condenatória (Brasil, 2018).

Esse é um perfil que expressa a seletividade por parte das forças de segurança e dos processos judiciais (Barcinski \& Cúnico, 2014). Assim, se antes a seletividade penal tinha como foco segmentos de baixa renda da população masculina, incluindo negros e pardos, nas últimas décadas,ampliou seu raio de ação para as mulheres com o mesmo perfil em meio à retração do Estado Social e o crescimento do Estado Penal(Germano, Monteiro, \& Liberato, 2018). A própria política de guerra às drogas é exemplo do avanço do Estado Penal no país, contribuindo com o aumento da taxa de criminalidade e o encarceramento feminino (Germano, Monteiro, \& Liberato, 2018). Ao que parece, ainda permanece no país a antiga prática, de herança colonial, em que para os mais abastados tolera-se suas práticas delituosas, compreendidas como erro ou falha e, portanto, passiveis de serem perdoadas ou abrandadas pela justiça, mas para população racializada e pobre cabe-lhes o rigor da lei com a prisão.

Esse contexto ajuda a compreender os vetores sociais e econômicos, além dos marcadores de seletividade (classe social e cor)que resultam no encarceramento de mulheres jovens, negras ou pardas, mães solteiras, de baixa escolaridade e renda. Isto posto, recorremos a Wacquant (1999) para salientar o quanto as prisões no Brasil são funcionais para a manutenção do controle e dominação de certas parcelas da população.Além disso, ressaltamos o quanto o poder punitivo que recai sobre as mulheres reflete-se em mais uma forma de intensificação do controle social e sexual dos corpos femininos (Germano, Monteiro, \& Liberato, 2018).

Davis (2018), ao debater o tema, realiza estreita conexão entre as expressões históricas do racismo e o meio lucrativo com que o sistema prisional opera sobre a população negra e pobre com sua estratégia punitiva. No que tange à população feminina, segundo a autora, o cárcere corresponde a uma ampliação do alcance dessas amarras socioculturais que pesam sobre o gênero feminino interseccionadas com inúmeros outros 
marcadores. Além disso, considera que a prisão, por ser historicamente racializada, tem intensificado sua lógica punitiva. Em sua análise, o racismo ainda influencia profundamente todas as estruturas e comportamentos da sociedade atual de tal maneira que não há como se pensar na eliminação do racismo sem que passe pela eliminação do próprio sistema prisional.

Adentrar, portanto, no universo de uma pesquisa-interventiva acerca da dura realidade que enfrentam as mulheres no sistema penitenciário brasileiro, requer olhares atentos que considerem $\mathrm{o}$ entrelaçamento de marcadores como gênero, raça, etnia, geração, classe, território, família, matrimônio, sexualidade, religião, além de outros (Oliveira, 2017). Além do mais, é preciso ter em conta a utilidade política da prisão para manutenção das relações de poder desde o nascimento da modernidade (Foucault, 2014a). Foi com base nesse horizonte político-epistemológico que realizamos a pesquisa de mestrado “Corpos encaliçados de prisão: mulheres e subjetividades em exceção", proposta pela primeira autora e orientada pelo segundo, com o objetivo de visibilizar como os marcadores, outrora assinalados, se agenciam e produzem efeitos nos processos de subjetivação de mulheres em uma penitenciária mista, localizada no Nordeste brasileiro. Como referem
Germano, Monteiro e Liberato (2018), tais "fontes de subordinação são centrais para entender o encarceramento em massa na atualidade, especialmente o feminino" ( $p$. 30), além de fazerem da prisão um espaço heterogêneo em que se conjugam diferentes poderes, agenciamento de forças e formas de singularização e resistência.

Para o presente artigo, focaremos num debate que consideramos urgente devido a invisibilidade que as experiências metodológicas, no geral, encontram nos relatos de pesquisa. Desse modo, propomos uma reflexão sobre os desafios metodológicos e formativos em pesquisaintervenção ao investigar as relações de poder que incidem sobre os corpos femininos na prisão. Partiremos, nessa reflexão, das experiências e problematizações, que nas palavras de Kastrup (2019), acabaram "articulando aprendizagem e atenção" (p.104) ao ensaiarmos certos modos de pesquisar/conhecer, atentos e abertos, para acompanhar processos e a experiência de se conectar com a potência de variação da vida, mesmo em espaços de confinamento como a prisão. O que apresentaremos, portanto, neste trabalho, são os caminhos investigativos percorridos, evidenciando tanto as memórias e narrativas construídas a partir da intersecção dos encontrosacontecimentos vividos com as mulheres no cotidiano da prisão, quanto os 
desdobramentos de tais experiências no modo como formamos pesquisadoras/es sob a perspectiva das pesquisasinterventivas.

Trata-se, como bem definiu Kastrup (2019), de um exercício de experimentação e reflexividade, de contato aberto e problematizador, "para sentir e se sentir (...) e se tornar sensível às coisas, a seu corpo e a si mesmo" (p. 104). Assim, tivemos que aprender a lidar com momentos de parada para o "cultivo da experiência atenta" (Kastrup, 2019, p. 105), para que pudéssemos dosar e trilhar os caminhos direcionados por um fazer acadêmico implicado com um rigor éticoestético-político de não se ater à busca por um dado pronto, mas de acompanhar processos, relações de força e de poderes e resistências que incidem sobre os corpos femininos na prisão. Além disso, apostar em modos de pesquisar encarnados por corpos e subjetividades de populações socialmente marginalizadas possibilita, a depender das escolhas metodológicas pretendidas, trilhar por caminhos que suscitem a "apreensão de movimentos coletivos de apropriação e invenção da vida que favoreçam a produção de existências singulares" (Paulon, 2005, p.21). Isso inclui reconhecer os próprios desdobramentos e provocações que a pesquisa com mulheres na prisão provoca, pois,de tão sufocantes, muitas vezes, resultou em múltiplos deslocamentos e interpelações sobre a forma como produzimos conhecimento, facilitando processos de singularização, criação e reexistência.

Por fim, entendemos que partilhar as inquietações vividas ao longo desse percurso pode, quem sabe, contribuir com um conjunto mais amplo de estudos que fazem crítica ao Sistema Prisional - não para sua reforma, mas para sua abolição -, além de fornecer novos elementos que auxiliem pesquisas com mulheres na prisão, e com o próprio campo de estudos da pesquisa-intervenção.

\section{Caminhos da Investigação}

A pesquisa esteve inspirada na perspectiva dos estudos foucaultianos acerca do poder e em diálogo com os pressupostos da pesquisa-intervenção. Em Michel Foucault, o poder é entendido como relação, enquanto relações de força, ação sobre ação ou sobre um conjunto de ações. Por isso não é propriedade de alguém ou de qualquer instância, pois é operatório, funcional, não sendo atributo nem de alguma instância/sujeito na posição de dominante, nem na de dominado, apesar de relacionar um ao outro. Na verdade, ele circula, transita, apresentando-se de modo difuso pelo campo social (Foucault, 2012). Embasados por esse entendimento sobre o poder, seguimos pelos 
pressupostos da pesquisa-intervenção,que nas palavras de Rocha e Aguiar (2003), é "uma tendência das pesquisas participativas que busca investigar a vida de coletividades na sua diversidade qualitativa" (p. 66). Mais do que um desenho metodológico no âmbito da pesquisa social, de acordo com as autoras,a pesquisa-intervenção propõe construir uma atitude diante da construção do conhecimento de modo a interrogar as múltiplas camadas de sentidos que sedimentam as instituições. Isso inclui questionar a própria instituição pesquisa,observando as relações de poder que a constitui e que nos atravessa enquanto pesquisadoras/res no exercício de nossas investigações.

Nesse sentido, a pesquisaintervenção afirma uma ética que, por sua ação crítica, resulta na ação de “desnaturalização permanente do objeto que se pretende conhecer, pela implicação do pesquisador, pelas contingências que acompanham as situações e seus efeitos pelo acontecimento" (Paulon \& Romagnoli, 2010, p. 94). Tal ação se reflete, ao mesmo tempo, em um êthos, pois enquanto experiência problematizadora, em vez de guiar a atenção pelo reconhecimento de algo, cabe a/ao pesquisadora/dor adotar uma postura estilística de pesquisa, com a experimentação de ideias, conceitos, percursos metodológicos, acompanhado de uma atitude problematizadora de si e do próprio fazer da pesquisa diante da realidade investigada (Ferreira Neto, 2015; Kastrup, 2019).

Tais preocupações metodológicas da pesquisa-intervenção dialogam com um importante problema filosófico, proposto por Foucault (2012), ao interrogar o próprio presente, no momento mesmo em que escreve, pensa ou se relaciona com sua época e com a ação que realiza, pois "consiste numa crítica do que somos, pensamos e fazemos, através de uma ontologia histórica de nós mesmos" (p.574). Nas palavras de Candiotto (2010) esta tarefa "consiste em apontar os limites históricos em torno da compreensão de quem somos em vista de sua ultrapassagem, da criação de novas modalidades de ser e de viver" (p. 124).

Considerando que a pesquisaintervenção se pauta por um trabalho compartilhado de modo a envolver os saberes dos sujeitos individuais e coletivos que compõem o plano de intervenção, no estudo proposto fizemos uso de observações, registro em diários de campo e entrevistas coletivas para a produção dos dados. Após as devidas autorizações institucionais e, posterior,com a autorização do Comitê de Ética em Pesquisa da Universidade Federal do Piauí (Parecer $\mathrm{n}^{\circ} 3.563 .778$ ), visitamos por um 
período de dez meses, ao longo do ano de 2019, a Penitenciária Mista Juiz Fontes Ibiapinapara realização do estudo. A inserção na referida unidade prisional previa a realização de observações nos diferentes espaços da prisão (pavilhão, celas, sala de aula, pátio, enfermaria, etc.). A negociação junto à diretoria foi facilitada pelo fato da primeira autora já ter trabalhado naquela unidade prisional como psicóloga. O acesso, assegurado por carta de autorização, permitia a permanência da pesquisadora no pavilhão feminino em pelo menos três dias da semana, durante uma hora ou uma hora e meia. As visitas aconteciam após procedimento padrão de vistoria, sendo que todo o trânsito na unidade era acompanhado por uma agente penitenciária.

Ressalta-se que ao longo da realização da etapa de campo, a unidade possuía por volta de 613 detentos, embora tivesse capacidade para somente 180 vagas. No caso das mulheres em cárcere o registro era de 56 (24 provisórias e 32 sentenciadas). Todas ficavam alojadas em um único pavilhão da unidade composto de 17 celas, um corredor e um pequeno pátio aos fundos para banho de sol. Originalmente o prédio da unidade era de um mercado público, que foi reformado para abrigar o presídio estadual e, posteriormente, adaptado de forma precária para receber mulheres presas. Por ser um ambiente marcadamente masculino e masculinizante, o presídio oferece condições mínimas para resguardar os direitos das mulheres presas, já que não conta com espaço para creche, para visitas familiares e íntima, etc.(Barcinski \& Cúnico, 2014).

Assim sendo, percorremos $\mathrm{o}$ pavilhão feminino regularmente em dias alternados da semana para acompanhar diferentes rotinas: visitas, aulas, eventos, banhos de sol, etc. Todas as observações e conversas foram registradas em diários de campo, analisando e acompanhando seus intercruzamentos com as experiências suscitadas na pesquisadora ao longo de todo o trabalho de campo realizado. É importante partilhar alguns imprevistos que ocorreram nesse ínterim, situação comum em pesquisas em unidades prisionais devido a dinâmica com as mudanças de protocolos de segurança e as tensões que habitam tais espaços. Como exemplo, citamos uma situação que passado um mês de realização de trabalho de campo, houve mudança na direção da unidade e todos os procedimentos de segurança foram modificados, tornando as regras e vistorias mais rígidas. Isso impossibilitou que as visitas ao presídio continuassem, pois, de acordo com a nova diretoria, pelo menos uma agente penitenciária deveria permanecer no pavilhão junto a pesquisadora, o que não 
foi possível devido a defasagem do quadro de pessoal. Assim, os encontros tiveram um hiato de um pouco mais de um mês, até novo regramento ser instalado e o acesso liberado.

Para a realização das entrevistas, a diretoria da unidade exigiu que fosse entregue um roteiro contendo os objetivos de cada encontro, duração e quantidade de participantes. Foi acordado que uma agente penitenciária ficaria responsável pelo deslocamento das participantes até a sala (de aula) em que seriam realizadas as entrevistas, com a lista dos nomes de quem participaria. Além disso, foi negociado que nesse momento a agente não ficaria na sala, para resguardar a condução dos trabalhos. As entrevistas coletivas foram divididas em seis encontros e os temas pensados a partir das vivências em campo e da releitura dos diários, a saber: relação com a justiça/ingresso no sistema prisional, saúde, maternidade, sexualidade, relacionamentos e "ser mulher" na prisão. Devido à dinâmica institucional, as entrevistas ocorreram em caráter aberto, de modo que em qualquer encontro poderíamos contar com novas participantes ou alguma poderia retirar-se caso desejasse. No geral, participaram entre 10 a 12 mulheres. Como elemento intercessor e disparador para os diálogos, iniciávamos os encontros sempre com trechos do livro "Presos que Menstruam” (Queiroz, 2015), de modo a suscitar identificações e reflexões por parte das participantes ao facilitar a emergência de relatos que traziam à tona suas histórias e realidades na prisão. Essa estratégia mostrou-se potente para acompanhar e analisar, por meio das narrativas e construção de um plano comum, as relações de força que incidiam sobre seus corpos e processos de subjetivação, mas também que expressavam as intensidades e singularidades do processo de re-existência de mulheres na prisão.

Conforme referimos anteriormente, daremos visibilidade neste artigo ao que se produziu no devir-pesquisadora/dor ao longo da construção dos caminhos investigativos experimentados a partir da tessitura da própria pesquisa, experiência essa atravessada pelas leituras, análises, orientações, e pela própria escrita do trabalho realizado. Tais experiências estiveram permeadas pelas marcas, os limites, as linhas de (des)continuidade e os desvios que nos constituíram pesquisadoras/res nesse campo de investigação. Para isso, reunimos os desafios metodológicas e formativos dessa experiência de pesquisa a partir dos seguintes blocos de discussão: modulações no corpo-experiência para cultivar outras percepções e aprendizagens no fazer-pesquisa; b) deslocamentos subjetivos e experimentações no caminhar 
da pesquisa; e c) deslocamentos de si no processo de escrita acadêmica coproduzida com mulheres na prisão.

Ressaltamos que as identidades das participantes constantes nos registros dos diários de campo e trechos das entrevistas foram preservadas com nomes fictícios. Alertamos ainda que em alguns momentos do texto alternamos o relato das experiências para a primeira pessoa do singular quando se trata de aspectos vividos pela primeira autora do artigo no campo de intervenção da pesquisa.

\section{Modulações No Corpo-Experiência Para}

Cultivar Outras Percepções E Aprendizagens No Fazer-Pesquisa

A decisão pelo estudo do encarceramento feminino e as relações de poder que se encontram emaranhadas nos espaços de confinamento remetem para a necessidade de construção de uma experiência atenta para lidarmos com um campo de investigação aberto diante da imprevisibilidade dos acontecimentos. A rigidez daquela estrutura e o predomínio de práticas disciplinares e hierarquias bem delimitadas, faz da prisão um espaço prenhe de limitações e barreiras diversas, que acabam resvalando na pouca autonomia para executar certos planos de pesquisa de natureza qualitativa, em especial do tipo interventiva, mesmo para aquelas/es que têm algum histórico de inserção/aproximação com a segurança pública e o sistema prisional (Bicalho, Rossoti, \& Reishoffer, 2016).

Deste modo, o primeiro desafio enfrentado foi tomar o percurso da pesquisa enquanto uma experiência estética. Kastrup (2010), baseada em John Dewey, qualifica que a experiência estética é um tipo de experiência que articula percepção e criação. Assim sendo, constitui-se como uma experiência que modula subjetividades de forma a suscitar aberturas e deslocamentos de âmbito: emocional, pois produz "sensações intensas" (Kastrup, 2010, p.40); prático,já que recoloca as "relações do corpo com o mundo" (p. 39); e cognitivo, ao depreender novos campos de sentido ao "cultivar uma forma especial de atenção" (p. 38) e acionar "processos de aprendizagem inventiva"(p.43).A autora ainda alerta que é uma experiência que "não se define pelo objeto a qual corresponde", pois pode estar relacionada a admiração de algo, uma obra artística, ou pode emergir da vida comum das relações tecidas no cotidiano (Kastrup, 2010, p.39).

Orientados por tais pistas, calibramos nosso olhar e o nosso corpo para nos colocar abertos à receptividade dessa experiência, naquilo que ela tem de potência para nos deixar impregnar e mergulhar nos encontros, experiências e aprendizagens do universo em que vivem 
as mulheres na prisão. Tal exercício foi importante para afastar os olhares prévios que nos habitavam antes mesmo de iniciar o trabalho de campo. Compartilhar espaços como o pavilhão, as celas, sala de aula e enfermaria, exigiu da nossa parte, ao acompanhar a rotina e conheceras demandas das mulheres na prisão, um tipo de atenção e aprendizagem sobre quais cenas ou situações nosso olhar deveria repousar com maior sensibilidade. As pistas que nos orientaram nesse exercício foram o grau de abertura permitido pelas entrevistadas, acerca de quais temáticas, situações e problematizações acolhiam e produziam ressonâncias, sinalizando assim para a construção de um plano comum de experimentação e análise sobre as relações de força que incidiam sobre os seus (os nossos) corpos e subjetividades na prisão. Um movimento de idas e vindas, gerador de dúvidas e inseguranças, mas que também permitia outros acessos aos territórios existenciais das participantes (não ditos, jogos de sentidos e sedução, desconfianças). Tal exercício exigia atenção, especialmente por parte da primeira autora, por ter tido maior acesso,dentre nós pesquisadoras/es,ao espaço da prisão. Neste caso, também me percebi tomada em meu corpo por vibrações, tensionamentos, experiências, problematizações e aprendizagens. É nesse sentido que retomamos a discussão trazida por Ferreira Neto (2017), proposta por Foucault, de que a pesquisa é um dispositivo de subjetivação. Para o filósofo, no trabalho de pesquisa, "sujeito e objeto se formam e se transformam", o que permite à(ao) pesquisadora/dor "se formar de outro modo, possibilitando que suas crenças, valores e perspectivas teóricas prévias, $\quad$ possam sofrer modificações”(Ferreira Neto, 2017, p.19).

Sob este mote, acompanhamos algumas modulações no processo de devirpesquisadora da primeira autora deste artigo, diante dos desafios metodológicos e formativos em pesquisa com mulheres na prisão. No que tange especificamente à relação entre a posição de pesquisadora e as mulheres presas, é importante ressaltar que, principalmente no início da pesquisa, havia certa desconfiança, provavelmente sustentada pela lógica imposta pela dinâmica institucional que se apresenta reforçadora de uma posição de poder/saber entre corpo técnico e as pessoas presas. $\mathrm{O}$ fato de a pesquisadora já ter atuado como psicóloga daquela unidade prisional reforçou, em algumas situações, esse entendimento entre as participantes, resultando algumas vezes em sentimentos de ameaça e insegurança.

Áurea senta de frente para o esposo em sua cela, que fica no fundo, próxima às celas da triagem. Sinto que a minha 
presença incomoda. Fico sem compreender... Será que pensam que estou vigiando-os? Ponho-me a pensar sobre o fato de que eu estava ali representando vários papéis: o de mulher "livre", de "psicóloga" e de um possível contato "estreito" com as agentes. Reconheço que não era uma delas, e isso certamente causava estranhamento, mesmo sendo mulher e ter tido abertura para conversarmos sobre muitas coisas, resultando certa cumplicidade (Diário de Campo, 30.01.2019).

Algumas agentes penitenciárias também enxergavam na figura da pesquisadora a possibilidade de esta exercer a função de vigilância e intervenção sobre as presas para que se mantivessem ordeiras e aprendessem a respeitar as normas sociais.

Numa conversa com uma Agente, para que eu participasse das aulas dos cursos profissionais, ela comenta que seria bom minha presença ali para que eu observasse as presas. Aquilo soou como um pedido para que as vigiasse ou que eu pudesse "dar jeito" nas meninas. Incomodo-me e tento elucidar qualquer não dito a esse respeito. Mas reconheço que em meio as políticas de subjetivação a que estamos engendradas/os, inclusive sob a lógica da racionalidade penal e seu desejo de punição, esta precisa ser descontruída permanentemente em nossos cotidianos e em nossos corpos (Diário de Campo, 01.02.2019).
Situações como essa indicam a importância de colocarmos sempre em análise nossas implicações, inclusive de forma coletiva,o que inclui colocar em crítica as relações de força que nos atravessam (e fazemos circular) no campo de intervenção. Daí a importância de estabelecer relações de cooperação e lateralidade com as interlocutoras do estudo, inclusive para visualizarmos nossas posicionalidades a partir dos marcadores que também nos engendram no campo social (Leite, 2014).

Ao longo da conversa, algo incomodava as meninas, parecia que queriam fazer algo, mas havia um obstáculo, o que comprovei no instante seguinte.Telma questiona a minha opinião sobre maconha. Como percebem que eu não repreendi nem estranhei, todas começam a rir, como em um alívio, e uma diz "Ah, então a gente pode fumar nosso baseado e você não vai se importar!?". Aproveito para,mais uma vez,reforçar nossa relação de confiança.Rapidamente, Telma começa a bolarum baseado e todas começam a compartilhá-lo entre si. Ficamos paradas ali conversando (como fosse por horas)sobre suas histórias, relacionamentos, lesbianismo, drogas etc. Elas me convidarampara me sentar no chão enquanto conversávamos. E sinto vontade de me aproximar, mas fico com receio das Agentes estranharemnossa movimentação. Uma 
das meninas percebe e, com cumplicidade,cede um banquinho para que eu fique mais próxima da roda de conversa. Em seguida, em meio a risadas e as histórias ali contadas, coloquei-me a pensar por quais implicações orientaram meus movimentos naquela manhã (Diário de Campo, 29.07.2019).

\section{O próprio campo investigativo} tratava de apresentar os limites e diferenciações existentes naquela relação, especialmente evidenciados em um fazer metodológico que visa desmontar perspectivas dualistas e universalizantes, dispositivos de poder e segmentações. Apesar de conhecer aquela unidade prisional, percorrê-la sob o olhar de uma pesquisadora preocupada com o não habitual, recalibrando a atenção a partir da experiência estética, tal inserção suscitou muitas interpelações que colocaram em análise as implicações que atravessavam o corpo de pesquisadora no trabalho de campo.

Além do mais, sabíamos da condição da população carcerária daquela unidade ser constituída em grande maioria por negros/as e jovens, advindos de contextos de miséria e marginalização. Mas, olhar para tal condição deslocandonos das representações que prefixam os sujeitos e que convocam a atenção para a experiência e singularização de como tais marcadores sociais engendram suas vidas, em especial as mulheres, foi importantíssimo para perceber os vetores de opressão e o controle estatal dentro das prisões e seus efeitos nos corpos e subjetividades femininos no cárcere. Tratase, nesse sentido, de uma opressão articulada que incide, inclusive, com mais brutalidade sobre os corpos de mulheres negras, assim como denunciado por Davis e Dent (2003) quando constatam o perfil repetitivo das mulheres encarceradas nos EUA e,também, no Brasil, demonstrando a similaridade entre as instituições prisionais em diferentes partes do mundo. Para as autoras, a prisão,além de punitiva, sexista e racista, opera por todo tipo de disciplina e controle dos corpos femininos mesmo reclusos em suas celas, atingindo-os com o disciplinamento moral, social e político das mulheres.

A presença majoritária de mulheres negras sob o poder punitivo do sistema de justiça criminal corresponde ao que Kilomba (2019) explicita quando fala de racismo institucional. Para a autora, há um tipo de diferenciação e hierarquização que confere um tratamento desigualem que sujeitos brancos possuem vantagens em relação aos grupos racializados em função das barreiras simbólicas que são impostas a estes últimos e que obstaculizam seu acesso, por exemplo, às políticas de direito e oportunidades. Naquela unidade prisional o racismo institucional se apresentava nos 
acessos diferenciados com que presas/os tinham em relação à garantia dos seus próprios direitos. As violações eram constantes, sendo que na população racializada que habita as prisões tais violações eram mais frequentes ainda, com o detalhe que as mulheres ainda eram subjugadas pelos próprios presos, no caso de presídios mistos.

Nessa direção, avançar na construção de uma pesquisa-interventiva diante da pluralidade de vidas que se intercruzavam nos mais diversos encontros ocorridos ao longo da realização da pesquisa, nos fez querer conhecer as segmentações que se assentavam naquela instituição e sobre os corpos e subjetividades femininas. Além disso, oportunizava a desconstrução de um olhar naturalizante sobre aquelas vidas. Neste exercício foi possível acompanhar as linhas de composição que tanto modulam a estrutura da prisão e sua forma de organização e regramentos (inclusive os não ditos), quanto agenciam, por diferentes linhas de força, os corpos que ali se encontram, sejam eles da equipe do administrativo, de segurança, técnico e dos/as detentos/as. Assim, produziam-se deslocamentos no corpo da pesquisadora na medida que fomos trilhando os caminhos da pesquisa, do olhar estritamente técnico-profissional, que acompanhou sua experiência ao longo dos anos que atuou profissionalmente no sistema prisional,para, a partir daquela experiência, passar a considerar as modulações do sistema capitalista excludente e discriminatório, que atravessam inclusive os trâmites penais, com a seleção da população que deveria ser mantida no cárcere, por meio de crivos raciais, sexistas e de classe. Aperceber-se desta analítica, influenciada pelas leituras propostas por Davis (2016, 2018), alinhando o sensível, o pensamento e o campo prático proporcionado pelo trabalho de campo realizado, suscitou novas entradas às memórias e experiências profissionais anteriores, com as quais o ato de pesquisar ia reencontrando e fazendo friccionar outros campos de sentido e problematizações, trazendo novos campos de visibilidade e dizibilidade provocados pelas redes de poderes multidirecionais que ali circulavam.

Em meio a essas redes, conformamse subjetividades que,em certa medida, se apresentam obedientes, neutralizadas e silenciadas pelos poderes que incidem sobre seus corpos, mas também vigilantes, atentas e realizadoras de ações de resistência, potentes de expressividade e reinvenção de si. Desse modo, reconhecer esta pesquisa enquanto dispositivo de subjetivação diante dos encontrosacontecimentos vividos com as mulheres na prisão, por meio das suas histórias e 
lutas, causou inúmeros deslocamentos no corpo de pesquisadora para apreender essa dimensão política de vida, mesmo na condição do cárcere. Vidas que teimavam em tentar interverter as relações de forças em meio as lutas cotidianas que travavam na prisão para re-existirem àquela estrutura. Relacionar tais elementos para compor o plano de análise, e também de aprendizagem, neste estudo, era urgente.

Como vimos, não só por linhas estratificadas foram compostas as análises. Também focamos nas estratégias do poder e nos pontos de luta que engendravam as subjetividades femininas, principalmente no que concerne ao controle de seus corpos e sexualidades naquele contexto. Tal analítica serviu, inclusive, para fazer ver o quanto essas linhas incidiam sobre a condição de pesquisadora na prisão. Houve momentos, durante a realização das entrevistas, em que podemos constituir um plano de análise tecido coletivamente com problematizações sobre os diversos aprisionamentos sociais e culturais impostos às mulheres dentro $\mathrm{e}$ fora da prisão para a manutenção de uma estrutura social sustentada pelo patriarcado, pelo machismo e pelo sexismo.

Labibe: - Quando um homem é preso, as mulheres ficam com os filhos, cuidam da casa. Já os homens não, dão os filhos pra mãe dele, manda pra casa da sogra. O homem não é forte o suficiente como a mulher é. Tem mulher que passa anos e anos visitando o marido, com um monte de menino, cuida da casa. Já o homem, não. Na primeira dificuldade que aparece, já diz que não consegue. E cai fora. Distribui os filhos e a mulher fica presa. (Trecho da Entrevista Coletiva, 16.10.2019)

Resguardas as particularidades, histórias como a de Labibe (e tantas outras que a pesquisadora escutava entre as grades da prisão) convergem com a vida de outras mulheres que se encontram no mundo lá fora. As marcas opressoras impostas pela moralidade religiosa, social e cultural de uma sociedade em que o homem se encontra na centralidade de todos os processos ainda é uma realidade para muitas de nós diante dos tantos "aprisionamentos" que tentam impor. E quanto mais marcadores de diferenciação e subalternização incidirem sobre os corpos femininos (mulheres negras, periféricas, de etnias diversas, não pertencentes a um padrão heteronormativo e cisgênero), mais subjugadas e sujeitas a violências diversas se encontram.

Por outro lado, é preciso ter cuidado com a ideia da "supermulher da pele escura" (Kilomba, 2019), que, segunda a autora, trata-se de uma estratégia política de silenciamento das dores e sofrimentos causados pelo racismo 
que exigem da mulher negra uma espécie de resiliência muda e intima diante dos inúmeros danos psicológicos e dificuldades vividos com as opressões que lhes marcam a vida. Ao reconhecer as lutas das mulheres negras e periféricas na prisão, é preciso se atentar, também, para as profundas feridas que carregam diante do racismo, da exclusão e da subalternização a que são submetidas diariamente.

Ana Maria: - Eu estou aqui dentro e minha mãe não vem me visitar por causa dos meus irmãos. Mas mesmo com isso eu tô sobrevivendo. E eu vou embora e vou mostrar que não precisei de nenhum deles. Eu vou mostrar pra eles que tô aqui dentro. Mas, como nenhum deles vieram...Eu nunca morri com a falta deles lá fora. Aqui dentro é que eu não morro. (Trecho da entrevista coletiva, 16.10.2019)

Essas foram reflexões que evidenciaram o quão próximas e, ao mesmo tempo, distantes estavam "pesquisadora" e "pesquisadas" naquele percurso investigativo. Cabia, então, reconhecer que a prisão atua como uma extensão mais concreta e totalizadora desses aprisionamentos, uma vez que ali assumem uma configuração bem mais intensa, realidade da qual a pesquisadora não compartilhava.
Sob este mesmo ponto de vista, os encontros também se mostravam potentes em desacomodar certos ideais feministas que conformavam a pesquisadora enquanto mulher antes de adentrar no trabalho de campo nesta investigação.Era comum a pesquisadora ser convocada pelas interlocutoras do estudo a se colocar e deslocar, enquanto mulher "livre", dos “aprisionamentos" a que estavam expostas. Estas foram experiências-acontecimento que, mais uma vez, remetiam à imprescindibilidade daquele que investiga ser trazido para dentro do campo de investigação, orientando-nos para uma análise de implicação em ato e não suscitado somente pela leitura dos diários de campo ou pelas memórias da pesquisa no momento da escrita (Paulon, 2005). Deste modo, também a pesquisadora não passou ilesa por esta experiência, pois, muitas vezes, foi deslocada e reposicionada na condição de também ser entrevistada ao ser questionada pelas próprias participantes acerca dos universos que a conformam mulher. Esta experiência encarnou no próprio corpo e território subjetivo da pesquisadora o questionamento acerca do "feminismo branco essencialista" (Gomes, 2016, p.19) que a conformava, mesmo já tendo certa leitura crítica a esse respeito e colocar-se no exercício de descolamento deste. 
Enquanto eu falava dos meus planos futuros e de como o casamento ainda não estava neles... Elas passaram a questionar os meus lugares de privilégio: branca, com curso superior, agora o mestrado, abastada etc. Mas ciente dos meus pertencimentos e privilégios e,apesar do meu engajamento, foi desconcertante ser confrontada ali, mesmo com minha atuação junto às pautas feministas (Diário de Campo, 28.02.2019).

Com isso, compreendia-se na pele o debate proposto por Davis (2016), sobre o fato de que muitas vezes o movimento feminista baseia-se em aspectos universais, resultando em lutas desiguais entre as mulheres ou, por vezes, negando, invisibilizando ou até hierarquizando diferenças de uma luta que é mais ampla. Por isso o alerta do "quanto é importante para os feminismos desvencilharem-se da noção de que há uma qualidade universal que podemos chamar de mulher" (Davis \& Dent, 2003, p.527). Como reflexão e aprendizado, entendia-se que uma coisa é o plano dos conceitos num exercício em que autores como Kastrup (2019) e outros chamam de política de recognição, outra é o reposicionamento de uma certa ideia ou compreensão a partir do campo emocional, prático e cognitivo, proporcionado pelo campo sensível que as interpelações da experiência estética geram. Tais questionamentos foram momentos de ruptura e desnaturalização de algumas representações que ainda carregávamos, sendo que aquelas mulheres ainda fizeramnos ver que o feminismo é construído por diferentes caminhos e que precisam estar em diálogo para terem suas legitimidades reconhecidas (bell hooks, 2019). ${ }^{1}$

Recuperando a ideia de que tanto o “sujeito"quanto o "objeto"de investigação se formam e se transformam no fazer da pesquisa, trataremos no próximo bloco de como as modulações de nossas percepções e aprendizagens ao longo deste estudo resultaram em outras experimentações metodológicas e formativas ao longo dessa investigação.

\section{Deslocamentos Subjetivos e Experimentações dos Caminhos da Pesquisa}

Investir em formas de pesquisar que assumam um caráter interventivo tratase de lidar com as mais diversas situações que o campo da pesquisa proporciona, afim de nos manter abertos ao convite a novas realidades e singularidades que emergem dos desconfortos, dos momentos de incômodo e ações desterritorializantes ali produzidos. Dessa forma, a pesquisa com mulheres no cárcere apontava para um trabalho sensível diante dos fluxos e mobilizações afetivas que emergiam da própria investigação e que direcionava o trabalho para o cultivo de uma experiência 
atenta para perceber (e nos perceber) nesse processo contínuo de trocas e encontros.

As escolhas metodológicas juntamente aos instrumentos utilizados para a escuta das mulheres e também de si, foram potentes vias de trabalho em que se buscava acompanhar processos $\mathrm{e}$ movimentos coletivos, uma forma de ouvir o estrangeiro, aquilo que difere dos esquemas práticos da recognição (Kastrup, Tedesco \& Passos, 2008).Tal exercício, como afirmado no bloco anterior, suscitou deslocamentos em nós, pesquisadores/as,para a experiência de reinvenção de si e de novas virtualidades atribuídas não somente àquilo que pertencia ao científico e acadêmico, mas da vida. Assim reafirmamos o paradigma ético-estético-político de se fazer pesquisa, possibilitando o trânsito dos devires, fluxos criativos e desterritorializantes, acolhendo a vida em sua variação (Barros, 2013).

Foi em meio a muitos momentos de partilha de afetos, sorrisos, memórias e aprendizados, mas também de deslocamentos e tensionamentos, que os encontros da pesquisa se deram.Dias em que, embora para as mulheres presas significassem, muitas vezes, uma mesmice rotineira, como diziam "aqui todo dia é igual", em nossos encontros relatavam o quanto se afastavam de uma noção de realidade estanque, sem variação. Ao acompanharmos o cotidiano da prisão e presenciarmos relações de conflito, amizade, brincadeiras, momentos de lágrimas e comemorações, registramos múltiplas formas de existência e de resistência frente às incidências dos poderes sobre seus corpos e subjetividades. Foram esses momentos que nos recobraram o exercício de crítica sobre qual posição pretendíamos assumir ao registrar essa experiência em um relato de pesquisa.

Assim, diversas foram as situações, falas e apontamentos vindos das participantes que nos (re)situaram acerca dos privilégios e condições de vida que representávamos e contrastavam com suas realidades anteriores e dentro da prisão. Nesse trânsito, também aprendemos a ficar atentos e reconhecer como alguns desses diferentes lugares e posições sociais se agenciam e nos produzem em nossas relações.

Em um certo momento da conversa com Lourdes, Helenira se aproxima e pergunta se tenho remédio pra cólica. Diz que está com muita dor. Lourdes começa a falar que ela deveria tomar três comprimidos anticoncepcionais de uma só vez que "ligeiro cortava", se referindo à interrupção do fluxo menstrual. Eu sinalizo, meio que no automática, do perigo que isso poderia acarretar para sua saúde. E rapidamente Lourdes responde "Ah, mas você tem vida de princesinha!" (Diário de Campo, 17.06.2019) 
Em outra situação, Maria Augustame responde com um olhar de cortar a alma: -é, mas ao final do dia, a gente fica $e$ você vai embora. (Diário de Campo, 08.08.2019)

Reconhecer que as narrativas ali apresentadas eram compostas por experiências racializadas e de histórias geralmente marcadas pela pobreza e pela violência, era fundamental e uma preocupação ético-política que orientou este estudo, inclusive para entender o quanto que o lugar social que certos grupos ocupam delimita relações e atribui experiências distintas (Ribeiro, 2017). Neste caso, reconhecer diferenças, privilégios e nos colocar na condição de aliadas/os dessas mulheres em suas lutas foi o que, aos poucos, foi fortalecendo nossas relações, sempre permeada de cuidados e cumplicidade, mas nunca fazendo-nos esquecer das diferenças e dos privilégios que nos distanciavam.

As entrevistas coletivas acabaram funcionando como espaço de problematização da realidade das mulheres na prisão. As falas das mulheres se apresentavam encarnadas por suas experiências, reflexões e aprendizagens, sendo inclusive formativa para nós pesquisadoras/res. Aproveitamos para registrar que nos momentos de encontro coletivo para a realização das entrevistas e naqueles mais "solitários", pertencentes às transcrições e análise do material produzido, a atenção voltava-se para as dúvidas sobre as escolhas e os caminhos traçados quanto a direção que a investigação ou a própria análise poderia tomar. Foi necessário, então, perceber que o desafio estava, justamente, no desprendimento das crenças acerca de uma suposta postura moral de como conduzir a pesquisa,para aprender com os próprios elementos/movimentos apresentados pelo campo de intervenção, por meio da temperatura dos diálogos e do grau de abertura que alcançávamos com o envolvimento das participantes em cada encontro realizado.

Jana: -Se eu falar, eu vou é chorar,

Dinalva: -É bom, as vezes alivia a alma. Alivia o coração. Tem gente que fala assim “ah, não vou chorar”, pois eu choro! Coloco tudo pra fora! Mas se for pra fazer, tem que ser com a pessoa certa. Todas que estavam aqui, ao ouvir a história dela, não sei se você observou no olhinho de cada uma que tava cheio de lágrima. Quem é a pessoa que não se emociona? $\mathrm{Eu}$ mesma sou derretida. (Trecho da entrevista, 16.10.2019)

Além disso, outras situações também foram geradoras de incertezas, desafios e até conflitos, como a dispersão e agitação das mulheres e a dificuldade em 
permanecerem "atentas" ao que era dito e exposto pelas outras participantes. A experiência demonstrou que enquanto a pesquisadora em campo esperava uma atenção focada, por parte das participantes, para o momento ali vivenciado; elas, sabiamente, revertiam a cena e as posições instituídas,convocando-a ao acompanhamento da composição de narrativas de forma mais livre, permitindo múltiplas entradas e saídas, pausas, desvios. Espécie de reversão das relações de força. Daí passamos a entender a necessidade de não ignorar nenhuma fala ou gesto, mesmos e apresentasse ideias fluídas, vagas, desfocadas do tema tratado em cada encontro. Assim, fazia-se necessário analisar a própria função da/o pesquisadora/dor que investiga, para que não enrijeça e tolha a participação, a fim de que se cumpra certa etapa da pesquisa anteriormente estruturada. Por isso é fundamental a preparação de cada encontro para que dialogue mais diretamente com as realidades daquelas mulheres, além de abrir espaço para possíveis avaliações e ajustes para o encontro seguinte. Logo, até mesmo por um compromisso ético, era fundamental que a pesquisadora se colocasse como aprendiz e pusesse em prática o exercício de estilística da pesquisa, ao ter que se reorganizar a todo instante para acompanhar constantemente os movimentos e os ritmos que nossas interlocutoras também imprimiam no corpo da pesquisa.

$\mathrm{O}$ ato de coletivizar as memórias e narrativas de vida das mulheres na prisão juntamente com as da pesquisadora em suas experiências tornou-se um momento de intensa criação, experimentação e afirmação da diferença. Para elas, era um momento de falar, assim como também servia para que se escutassem e se reconhecessem como produtoras de conhecimento e como pessoas capazes de se fazerem ouvir. Não era a pesquisadora quem estava lá para falar e ser ouvida, atribuída do lugar de um certo especialismo. Eram elas, as mulheres em situação de cárcere, quase nunca escutadas pela sociedade, que afirmavam de forma direta o modo como percebiam o mundo e a si mesmas sob a dinâmica das relações de força que percorriam seus corpos e subjetividades dentro e fora da prisão. E nessa troca mútua, ao ouvi-las, o olhar voltava-se para nós mesmos provocando rupturas, abrindo brechas, produzindo experiências novas e alteridade sobre o exercício das ações de pesquisa. Ali experienciamos momentos significativos sobre aquilo do qual falava Rolnik (1993) sobre a "gênese de um devir" (p. 242). Mas do que ideias, abstrações, são marcas inscritas no corpo. E, neste caso, considerando tanto as marcas dos corpos das mulheres encarceradas quanto aquelas 
trazidas, em especial, pelo corpo da pesquisadora que acompanhou mais diretamente a realização do trabalho de campo, eram passagens, em potencial, para abertura a um novo corpo.

Dessa maneira, o aspecto interventivo da pesquisa não se dá direta e necessariamente sobre esse ou aquele sujeito que se investiga/participa da pesquisa, mas no que se produz no entremeio,na relação dos encontros e singularidades dos corpos que participam da pesquisa.Como diria Foucault (2014b), os sujeitos são encarnações de singularidades, e são as relações de poder que conduzem tais singularidades. $\mathrm{O}$ caráter interventivo da pesquisa se apresenta, portanto, no deslocamento e na inversão, mesmo que transitória, das relações de força e das relações que se produz entre as singularidades que emergem no plano de análise e intervenção da pesquisa. Até porque, como vimos,as posições de quem compõe o plano de intervenção ou mesmo de análise nas pesquisas-intervenção, muitas vezes, deslizam e abrem novos possíveis para os planos da pesquisa.

\section{Deslocamentos de Si e o Processo de Escrita Acadêmica}

Nesse trabalho de experimentação de uma pesquisa com mulheres na prisão, tomamos a escrita enquanto proposta de escrita-experiência no sentido de provocar fissuras e deslocamentos sobre quem escreve, espécie de exercício de si. Assim, tanto os caminhos da investigação quanto o processo de escrita resultaram "num potencial instrumento de mudança de certo estado de coisas e instaurador de novas realidades" (Ferreira Neto, 2015, p.415).

Nesse sentido, o uso dos diários de campo, pelas várias possibilidades de entrada que portam, foi fundamental para orientação acerca da analítica dos regimes de poderes na prisão e, sobretudo, para colocar em análise nossas implicações no processo da pesquisa. Dessa forma, o registro das memórias e cenas vividas ao longo dos quatro anos de trabalho profissional no sistema prisional, por parte da primeira autora, e ao longo do período de permanência no campo enquanto pesquisadora, como também o exercício de interlocução com as múltiplas vozes que participaram deste trabalho, foram fundamentais para compreender a função deste dispositivo provocador de análises, enquanto disparador de desdobramentos múltiplos da pesquisa (Kastrup \& Barros, 2009).

Os diários, além dos registros das observações e cenas vividas ao longo da investigação, guardaram as implicações, os incômodos e reflexões instigados no campo de intervenção, para que fossem colocados em análise e permeasse a 
produção da escrita da pesquisa. Mas é preciso que se diga que os diários, pelo menos nas pesquisas-intervenção, não podem ser entendidos como repositórios da memória. Enquanto dispositivo, abre um campo frutífero, como diria Foucault (2014b) sobre a hupomnêmata de Plutarco, para se "ler, reler, meditar, conversar consigo mesmo e com os outros" (p. 148). Assim, os diários não se colocam com uma narrativa de si mesmos, mas de muitas vozes que se intercruzaram nesse percurso, constituindo,desta forma,num importante corpus analítico dos trabalhos de pesquisaintervenção.Nesse aspecto, a composição dessas múltiplas narrativas acompanhada dos exercícios de reflexão sobre os encontros vividos na prisão, correspondem em uma coprodução coletiva formando um plano de escrita de múltiplas entradas e saídas analíticas.

Em meio a esta experiência, destacamos dentre outros desafios para a composição desse tipo de registro, as ressonâncias e os desdobramentos que o próprio ato de uma escrita implicada produz, seja durante o registro das observações e das conversas realizadas, seja no momento de revolver tais memórias e registros para compor a escrita da pesquisa. Tais ressonâncias auxiliaram inclusive no acompanhamento das modulações do processo de devirpesquisadora/dor ao apostarmos no cultivo de uma experiência estética ao longo dos caminhos tomados pela investigação. Esse exercício, sem dúvida, abriu-nos para a experiência de uma aprendizagem inventiva em todas as chamadas "etapas" do estudo e na composição da escrita do trabalho.

Para isso foi importante o entendimento de que era preciso ter bastante evidente a baliza de qual política cognitiva afirmávamos com a realização desse estudo: se "encarnada" por linhas da "experimentação inventiva" ou "rebatizada por subjetividades recognitivas" (Kastrup, 2005, p. 1281). Nesse sentido, foi necessário um esforço para tentar sustentar o foco na ação problematizadora não apenas diante dos momentos de encontro com as participantes, mas ao longo da ação de análise e escrita do trabalho, até mesmo para retomar possíveis estranhamentos e abertura de sentidos suscitados pelas intervenções produzidas pelas participantes, com rupturas e inversões de relações de força diante situações em que lhes foi confiscado pertences, direitos e sua dignidade. Retomar tais elementos, com a força que o material produzido portava para interpelar a atualidade da condição das mulheres nas prisões, exigia dos nossos atos de escrita,ao revolver os registros e análises desses diários,também uma aprendizagem e experimentação inventivas, para que tivéssemos o cuidado 
de não recairmos no afã da representação tão desejada pelo establishment acadêmico(Dell'Aglio, Sbeghen, \& Heinze, 2019).

$\mathrm{O}$ ato de registrar aquilo que se viveu no campo de intervenção, ou transcrever as memórias que emergiam da pesquisadora ao recordar-se da sua atuação profissional no ambiente carcerário, indicavam com maior especificidade para a não separabilidade das singularizações ali produzidas entre o corpo das mulheres, que, de algum modo, se encontravam $\operatorname{com}(\mathrm{e}$ interpelavam) o corpo da pesquisadora ao habitar, mesmo que temporariamente, aquele espaço.Desse modo, além de acompanhar com base nesses registros as relações de poder e os processos de subjetivação ali engendrados, a partir dos encontros e desencontros que o cárcere produz, acabamos percebendo, pelas ressonâncias e desdobramentos provocados, que nós pesquisadoras/res também estávamos a ser (des)subjetivados ao longo dessa experiência.

Cabia, nesse sentido, operar com uma atenção extensiva e intensiva sobre aquilo que também agenciava e incidia sobre nós, produzindo experiências de alterização, tornando possível perceber os limites e o modo como nos constituímos pesquisadoras/es. Decerto, foi com o caminho de composição da escrita do trabalho que o ato de pensar a pesquisa enquanto dispositivo de subjetivação ficou mais explícito. Assim, nos demos conta de que $o$ ato de uma escrita implicada possibilita a entrada no universo de outras subjetivações,suscitadas pelo o que Foucault (2014b) chamou de"subjetivação do discurso" (p. 48).

Isto posto, o desafio de outrar-se diante de certa forma de conduzir a escrita acadêmica ancorada na representação da ordenação do real, do tipo que exclui ou faz velar o irregular, o inesperado, enfim, o intensivo da experiência; e, ao mesmo tempo, de nos lançar diante das possibilidades de abertura para o exercício da experiência do acontecimento da escrita, passou a ser uma constante no trabalho. Inclusive, por tentarmos afirmar uma ética e um êthos ao longo de todo o processo de escrita acadêmica (Kastrup, Tedesco \& Passos, 2008).Certamente que avançamos em alguns momentos, noutros não. Apesar disso, continuamos na aposta do exercício de liberação de algumas das amarras aqui referidas e na tentativa de exercer tal ação estilística da pesquisa e da escrita acadêmica.

Provocados pelo encontro com corpos que ora se apresentavam aprisionados e sufocados, ora como frágeis e amedrontados, mas também indignados, curiosos,que vibravam e que se colocavam resistentes e em re-existência diante dos absurdos e das violências cotidianas com 
que as mulheres e outros vivem nas prisões, esta foi a baliza ética que nos orientou em todo o trabalho. Foram experiências que nos ajudaram a colocarem análise nossos corpos marcados pela branquitude, por certas feminilidades e masculinidades, assentados em alguns privilégios, mesmo que frágeis a depender das conjunturas e relações de força que nos perfilam. Por outro lado, foram experiências que também nos auxiliaram a perceber outras estratégias e relações de poder que tentam conformar nossos corpos na academia e de nos governar enquanto pesquisadoras/espor meio das políticas de pesquisa e pelos editais de fomento das agências de financiamento.

Como diria Foucault (2014b) é a "própria alma que é preciso criar no que se escreve" (p.152). Nesse sentido, escrever sobre as experimentações e aprendizagens que os caminhos e os desafios metodológicos percorridos ao longo desta pesquisa suscitaram, reforça a necessidade de continuarmos a apostar em modos de pesquisar e formar pesquisadoras/es abertos ao "entendimento da pesquisa enquanto um processo vivo" (Dell'Aglio, Sbeghen, \& Heinze, 2019, p.42).

\section{Notas}

${ }^{1}$ Bell Hooks, autora reconhecida e aclamada da luta feminista negra, cujo nome de registro é Glória Jean Watkins, optou pelo pseudônimo "bell hooks" em homenagem a sua bisavó, Bell Blair Hooks. Porém, utiliza a escrita de seu nome com letra minúscula como forma de deslocar o foco para suas ideias e escrita e não à figura autoral.

\section{Referências}

Barcinski, M., \& Cúnico, S. D. (2014). Os efeitos (in)visibilizadores do cárcere: as contradições do sistema prisional”. Psicologia, 28(2), 6370. Recuperado de http://www.scielo.mec.pt/pdf/psi/v2 8n2/v28n2a06.pdf.

Barros, R.B. (2013). Entrada Grupal: uma escolha ético-estético-política. In R.B. Barros. (2013). Grupo: a afirmação de um simulacro (pp.315-324). Porto Alegre: Sulina.

Bicalho, P.P.G., Rossoti, B.G..P., \& Reishoffer, J.C. (2016). A pesquisa em instituições de preservação da ordem. Polis e Psique, 6(1), 85-97. doi: https://doi.org/10.22456/2238152X.61384.

Brasil. (2019). Ministério da Justiça e Segurança Pública. Levantamento Nacional de Informações Penitenciárias (Infopen). Brasília, DF: Departamento Penitenciário Nacional. Recuperado de: https://www.gov.br/depen/ptbr/sisdepen/maisinformacoes/relatorios-infopen. 
Brasil. (2018). Ministério da Justiça e Segurança Pública. Levantamento Nacion. Levantamento Nacional de Informações Penitenciárias (Infopen Mulheres, $2^{\circ}$ ed.). Brasília, DF: Departamento Penitenciário Nacional. Recuperado de: https://www.gov.br/depen/pt$\mathrm{br} / \mathrm{sisdepen} / \mathrm{mais}-$ informacoes/relatorios-infopen.

Candiotto, C. (2010). Foucault $e$ a crítica da verdade. Belo Horizonte: Autêntica.

Davis, A. (2016). Mulheres, Raça e Classe. (H.R. Candiani, Trad.). São Paulo: Boitempo.

Davis, A. (2018). Estarão as prisões obsoletas?. (M. Vargas, Trad.). Rio de Janeiro: Difel.

Davis, A., \& Dent, G. (2003). A prisão como fronteira: uma conversa sobre gênero, globalização e punição. Revista Estudos Feministas, 11(2), 523-531. doi: https://dx.doi.org/10.1590/S0104026X2003000200011

Dell'Aglio, D.D., Sbeghen, E.P.D, \& Heinze, R.B. (2019). Inquietações éticas: sobre a possibilidade de (des)encontros. Polis e Psique, $\mathrm{n}^{\mathrm{o}}$ especial: 20 anos do PPGPSI/UFRGS, 36-53. doi: https://doi.org/10.22456/2238152X.97767.
Ferreira Neto, J. L. (2015). Pesquisa e Metodologia em Michel Foucault.Psicologia: Teoria $e$ Pesquisa,31(3), 411-420.doi: https://dx.doi.org/10.1590/0102$\underline{377220150321914100420 .}$

Ferreira Neto, J. (2017). A Analítica da Subjetivação em Michel Foucault. Revista Polis e Psique, 7(3), 7-25. doi:https://doi.org/10.22456/2238152X.76339.

Foucault, M. (2012). Estratégia, podersaber. Ditos e EscritosIV. Paris: Gallimard.

Foucault, M. (2014b). Ética, sexualidade e política. Ditos e Escritos V. (E. Monteiro \& I.A.D. Barnosa., Trad.) Rio de Janeiro: Forense Universitária.

Foucault, M. (2014a).Vigiar e punir: história da violência nas prisões. (42․ed). (R. Ramalhete, Trad.) Petrópolis: Vozes.

Ferraz, H. G., \& Joffily, T. (2019). Democracia e encarceramento em massa: provocações de teoria política ao estado penal brasileiro. Revista Brasileira de Ciências Criminais, 152,383-422. Recuperado de https://www.academia.edu/3825488 6/.

Germano, I. M. P., Monteiro, R. A. F. G., \& Liberato, M. T. C. (2018). 
Criminologia Crítica, Feminismo e Interseccionalidade na Abordagem do Aumento do Encarceramento Feminino. Psicologia: Ciência e Profissão, 38(spe2), 27-43. doi: https://doi.org/10.1590/1982$\underline{3703000212310}$

Gomes, C. M. (2016). Corpos negros e as cenas que não vi: Um ensaio sobre os vazios de uma pesquisa criminológica situada. Sistema Penal \& Violência, 8(1), 16-28. doi: https://doi.org/10.15448/21776784.2016.1.23717.

hooks, bell. (2019). O feminismo é para todo mundo: políticas arrebatadoras. (H. Libanio, Trad.). Rio de janeiro: Rosa dos Tempos.

Kastrup, V. (2005). Políticas cognitivas na formação do professor e o problema do devir-mestre. Educação \& Sociedade, 26(93), 1273-1288.

doi:https://dx.doi.org/10.1590/S010 $\underline{1-73302005000400010 .}$.

Kastrup, V. (2010). Experiência estética para uma aprendizagem inventiva: notas sobre o acesso de pessoas cegas a museus. Informática na Educação: teoria e prática,13 (2), 38-45.

doi: https://doi.org/10.22456/19821654.12463.

Kastrup, V. (2019). A atenção cartográfica e o gosto pelo problema. Polis e Psique. $\mathrm{N}^{\circ}$ especial: 20 anos do
PPGPSI/UFRGS,

99-106. doi:https://doi.org/10.22456/2238152X.97450 .

Kastrup, V., \& Barros, R. B. (2009). Movimentos-funções do dispositivo na prática da cartografia. In E. Passos, V. Kastrup, \& L. Escóssia (Orgs.), Pistas do método da cartografia: Pesquisa-intervenção e produção de subjetividade (pp. 76-91). Porto Alegre: Sulina.

Kastrup, V., Tedesco, S., \& Passos, E. (2008). Políticas da Cognição. Porto Alegre: Sulina.

Kilomba, G. (2019). Memórias da Plantação: episódios do racismo cotidiano. ( $1^{\circ}$.ed.). (J.Oliveira, Trad.). Rio de Janeiro: Cobogó.

Leite, M. (2014). Cartografar (n)a prisão. Estudos e Pesquisas em Psicologia, 14(3), 795-813.

doi:

https://doi.org/10.12957/epp.2014.1 3883.

Oliveira, C. B. (2017). A mulher em situação de cárcere: uma análise à luz da criminologia feminista ao papel social da mulher condicionada pelo patriarcado. Porto Alegre: Fi.

Paulon, S. M. (2005). A análise de implicação com ferramenta na pesquisa-intervenção. Psicologia \& 
Sociedade, 17(3), 18-25. doi: https://dx.doi.org/10.1590/S010271822005000300003.

Paulon S.M., \& Romagnoli R.C. (2010). Pesquisa-intervenção e cartografia: melindres e meandros metodológicos. Estud. Pesqui. Psicol., 10(1), 85-102.doi: https://doi.org/10.12957/epp.2010.9 $\underline{019}$.

Queiroz, N. (2015). Presos que menstruam. Rio de Janeiro: Record.

Ribeiro, D. (2017). O que é lugar de fala?. Belo Horizonte: Letramento.

Rocha, M. L. da, \& Aguiar, K. F. de. (2003). Pesquisa-intervenção e a produção de novas análises. Psicologia: Ciência e Profissão, 23(4), 64-73. doi: https://doi.org/10.1590/S141498932003000400010.

Rolnik, S. (1993). Pensamento, corpo e devir. Uma perspectiva ético/estético/política no trabalho acadêmico. Cadernos de Subjetividade, 1(2), 241-251.

Santos, S.D.S. (2019). A crise do sistema carcerário brasileiro em perspectiva: análise sob o paradigma crítico-criminológico. VirtuaJus, 4(7),138-157. doi: https://doi.org/10.5752/P.16783425.2019v4n7p138-157.
Wacquant, L. (1999). As prisões da miséria. Paris: Raisons d'Agir.

Zaffaroni, E.R. (2013). A questão criminal. ( $1^{\circ}$. ed.). Rio de Janeiro: Revan.
Caroline Cabral Nunes é psicóloga pela Universidade Estadual do Piauí (UESPI) e mestra em Psicologia pela Universidade Federal do Piauí. É também membra do Núcleo de Pesquisa e Intervenção em Psicologia Crítica e Subjetivação Política Nupolis.

E-mail: carolcabral n@ hotmail.com

ORCID: http://orcid.org/0000-0001-9008$\underline{0144}$

João Paulo Macedo é docente do departamento de Psicologia e do Programa de Pós-Graduação em Psicologia da Universidade Federal do Delta do Parnaíba, coordenador do Núcleo de Pesquisa e Intervenção em Psicologia 
Crítica e Subjetivação Política (Nupolis) e bolsista Produtividade do CNPQ.

E-mail: jpmacedo@ufpi.edu.br

ORCID: http://orcid.org/0000-0003-4393-

$\underline{8501}$

Enviado em: 29/05/20 - Aceito em: 02/10/20 